\title{
Class III Malocclusion Treated by Combined Orthodontic and Orthognathic Approach Along with Growth Prediction: A Case Report
}

\author{
Vaibhav Gandhi' (D), Falguni Mehta² (D), Dolly Patel ${ }^{3}$ (D) Harshik Parekh² (D) Hrishabh Joshi² (D)
}

\author{
'Department of Orthodontics, UCONN health center, Connecticut, USA \\ ¿2Department of Orthodontics, Government Dental College and Hospital, Ahmedabad, India \\ ${ }^{3}$ Department of Orthodontics, AMC Dental College, Ahmedabad, India
}

Cite this article as: Gandhi V, Mehta F, Patel D, Parekh H, Joshi H. Class III Malocclusion Treated by Combined Orthodontic and Orthognathic Approach Along with Growth Prediction: A Case Report. Turk J Orthod 2020; 33(1):65-71.

\begin{abstract}
To devise a comprehensive treatment strategy for patients with Class III malocclusion, it is critical to address etiology in the process of differential diagnosis. Growth prediction has always been a part of the deduction science. It is important not only in treatment planning and treatment provision, but it is equally important in the evaluation of prognosis during retention and after retention. The visual treatment objective by Ricketts is a complete analysis and the first of its kind defining every aspect of malocclusion and also assessing where the etiology lies. Here, we present one such case of skeletal Class III in which the growth prediction has played a vital role in the comprehensive treatment planning and treatment outcome.
\end{abstract}

Keywords: Growth prediction, orthognathic surgery, skeletal discrepancy

\section{INTRODUCTION}

The incidence of Class III malocclusion comprises a meager amount of the average orthodontic practice, but these are among the most demanding and at the same time rewarding cases to treat effectively and comprehensively. In the bygone days, Class III malocclusions were believed to be solely due to the prognathic mandible (1). Present knowledge of etiology has revealed that it can occur due to maxillary retrognathism, mandibular prognathism, or a combination of both. Another possible etiology can be due to a centric relation-centric occlusion shift leading to a mesial shift of the lower arch in the truancy of a true maxillomandibular skeletal discrepancy (pseudo-Class III). Therefore, the treatment strategy must be devised considering a myriad of factors such as the growth status, age, the severity of the skeletal dysplasia, severity of dental malocclusion, and patient compliance. According to a systemic review and meta-analysis conducted by Daniel et al. (2), the average prevalence of Class III malocclusion in combined sample of all races is $7.04 \%$ with a range from 0 to $26.67 \%$. Populations from Southeast Asian countries showed the highest Angle's Class III malocclusion prevalence rate of 15.80\% (3-7). The European studies had an average prevalence rate of $4.88 \%$, and Indian populations had the lowest prevalence rate of $1.19 \%(6-8)$.

To devise a comprehensive treatment strategy for Class III patients, it is critical to address etiology in the process of differential diagnosis. Growth prediction has always been a part of the deduction science. Baumrind has rightly said that the ability to predict assists the orthodontist psychologically in the treatment-planning process by removing the socalled art and adding a little more of science (9). The amount and direction of facial growth have long been regarded as the key factor in determining the success or failure of orthodontic treatment. The ability to predict craniofacial growth will accurately improve the reliability of treatment planning $(10,11)$. It is not possible to know where to position the 
teeth unless it is known where the bony bases will be during and at the end of treatment. Growth prediction is important not only in treatment planning and treatment provision, but it is equally important in the evaluation of prognosis during retention and post retention $(12,13)$. Evaluation of the visual treatment objective (VTO) by Ricketts is a complete analysis and, to the best of our knowledge, the first of its kind defining every aspect of malocclusion and resolv-

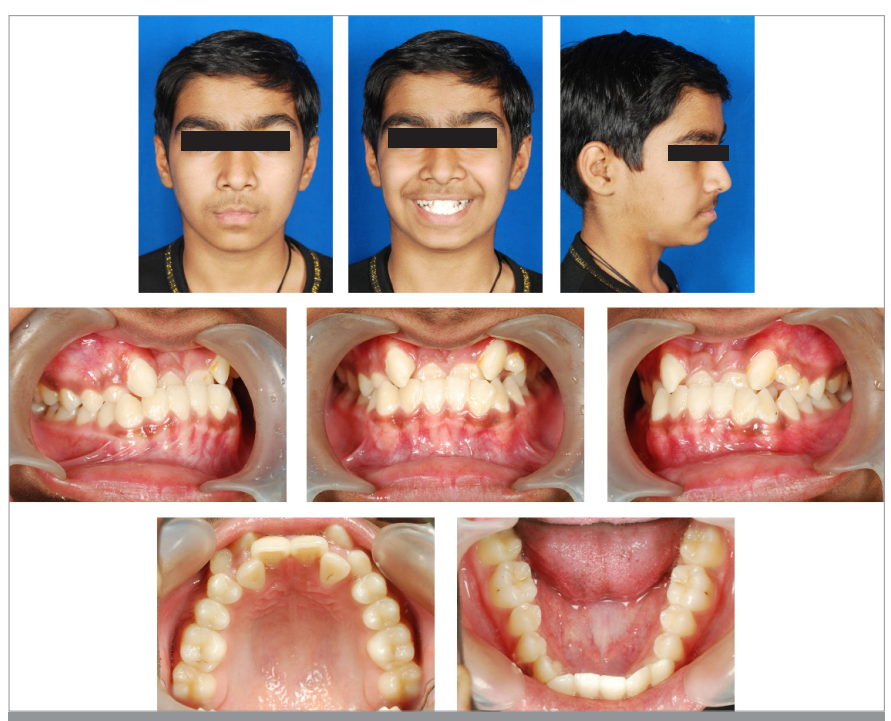

Figure 1. Pretreatment photographs

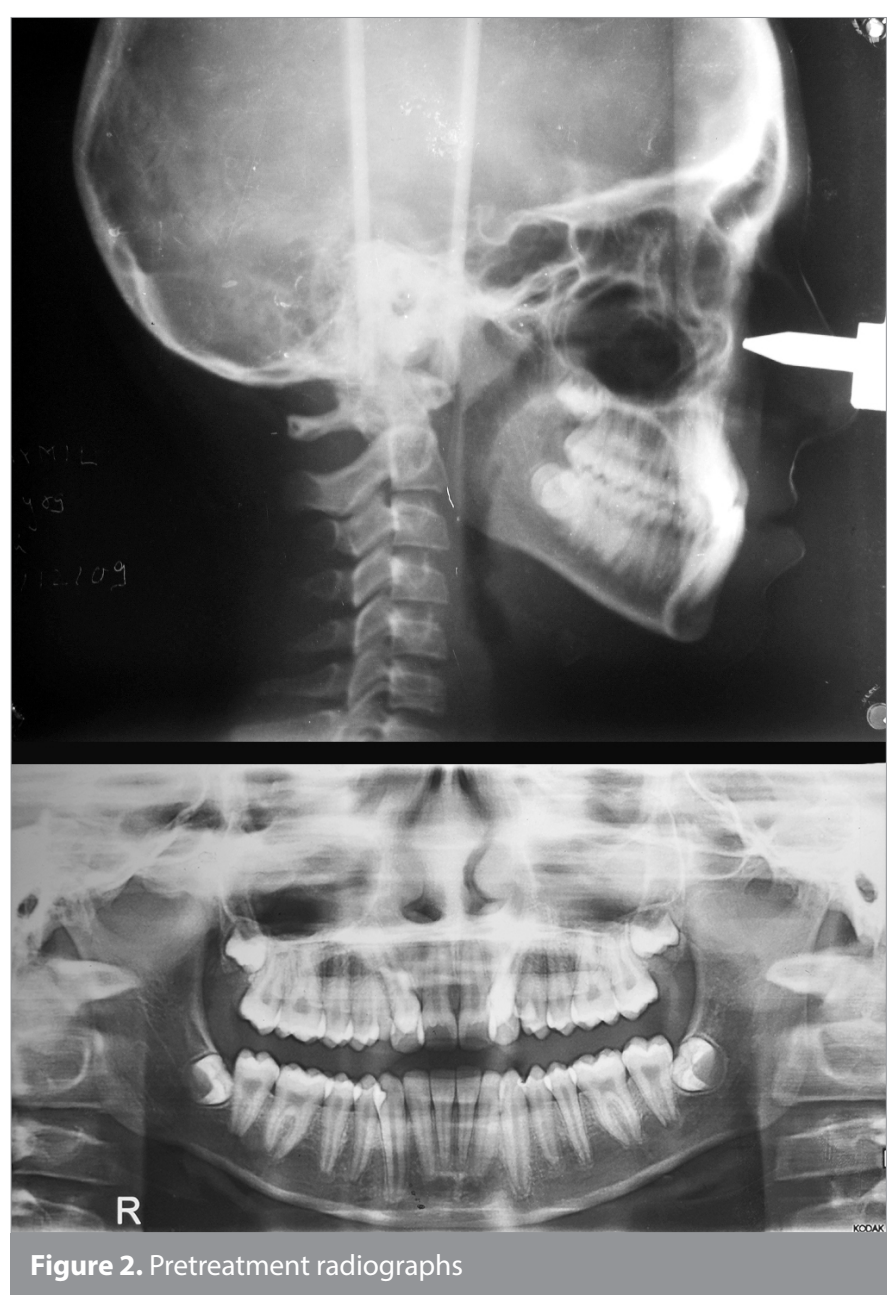

ing the etiology where it actually lies. Using this method, the behavior of the mandible was predicted in 52 of the 55 patients with a $96 \%$ accuracy rate (14). Ideally, it is desirable to come up with a ratio that can directly predict soft tissue changes form hard tissue movement, but due to significant variation in the soft tissue profile between individuals, it will not be possible to accurately measure such changes. Furthermore, it is important to predict soft tissue changes that can occur with maxillary advancement surgery. Misdiagnosis of soft tissue responses with maxillary advancement surgery can result in an undesirable esthetic outcome (15).

Here, we are presenting one such case of skeletal Class III in which growth prediction has played a vital role in the comprehensive treatment planning and treatment outcome.

\section{Etiology and Diagnosis}

A 14-year-old male patient came to the Department of Orthodontics and Dentofacial Orthopedics with the chief complaint of irregularly placed upper front teeth. On extraoral examination, the patient had a mesoprosopic facial type with competent lips and nonconsonant smile arc. The patient had a straight soft tissue profile. Intraoral examination showed (super) Class I molar relation bilaterally. The upper central incisors were in crossbite and the lateral incisors were palatally blocked out (Figure 1). The model analysis revealed $13 \mathrm{~mm}$ crowding in the upper arch, and the lower midline had shifted toward the right side by $2 \mathrm{~mm}$. the overbite was $6 \mathrm{~mm}$, the reverse overjet was $2.5 \mathrm{~mm}$, and the curve of Spee was $2.5 \mathrm{~mm}$. Furthermore, there were retroclined lower incisors. All these features suggested a typical case of Class III malocclusion in growing age. A cephalometric analysis revealed that patient was having skeletal Class III malocclusion ( $\mathrm{ANB}=-3^{\circ}$, Wits appraisal $=-4 \mathrm{~mm}$ ) with horizontal growth pattern $\left(\mathrm{FMPA}=22^{\circ}, \mathrm{GoGn}\right.$ to $\left.\mathrm{SN}=27^{\circ}\right)$ and proclined upper and retroclined lower incisors (upper incisor to $\mathrm{NA}=30^{\circ}$, lower incisor to $\mathrm{NB}=17^{\circ}, \mathrm{IMPA}=86^{\circ}$ ). Grummon's cephalometric analysis disclosed the underlying skeletal mandibular asymmetry (Ag-Me: right $44 \mathrm{~mm}$ and left $53 \mathrm{~mm}$, Me-MSR linear: $6 \mathrm{~mm}$ ) (Figure 2). Based on clinical and cephalometric findings, our diagnosis was Angle's (Super) Class I molar relation superimposed over skeletal Class III base relation due to retrognathic maxilla and orthognathic mandible with horizontal growth pattern, crossbite in relation to upper central incisors, and palatally displaced lateral incisors, over retained maxillary deciduous canines, straight soft tissue profile, and nonconsonant smile arc, as well as skeletal mandibular asymmetry supported by Grummon's analysis (Figure 1, 2) (Table 1, 2).

After meticulous calculations and reaching the diagnosis, the next critical step was devising a comprehensive treatment plan. At this conjecture, there were a few possible treatment alternatives, but the use of Rickett's growth prediction helped us to choose the most appropriate treatment plan.

\section{Treatment Alternatives}

Nonextraction, nonsurgical treatment with rapid palatal expansion and facemask followed by extraction of upper first premolars and fixed orthodontic treatment.

Since the cephalometric data of this patient indicated a retrognathic maxilla, a facemask would have been an option to correct 
maxillary sagittal retrognathism. But the ideal time for facemask therapy is 8-9years of age, and this patient was 14 years old, and that was one of the reasons for not considering this approach.

Extraction of upper first premolars, decompensation and surgical maxillary advancement, and asymmetric mandibular setback, which would be the treatment that would address all the problems in this case.

In our surgical treatment objective (STO), the patient's soft tissue profile was not looking pleasant with only maxillary advancement, and furthermore, the patient had asymmetric mandibular growth.

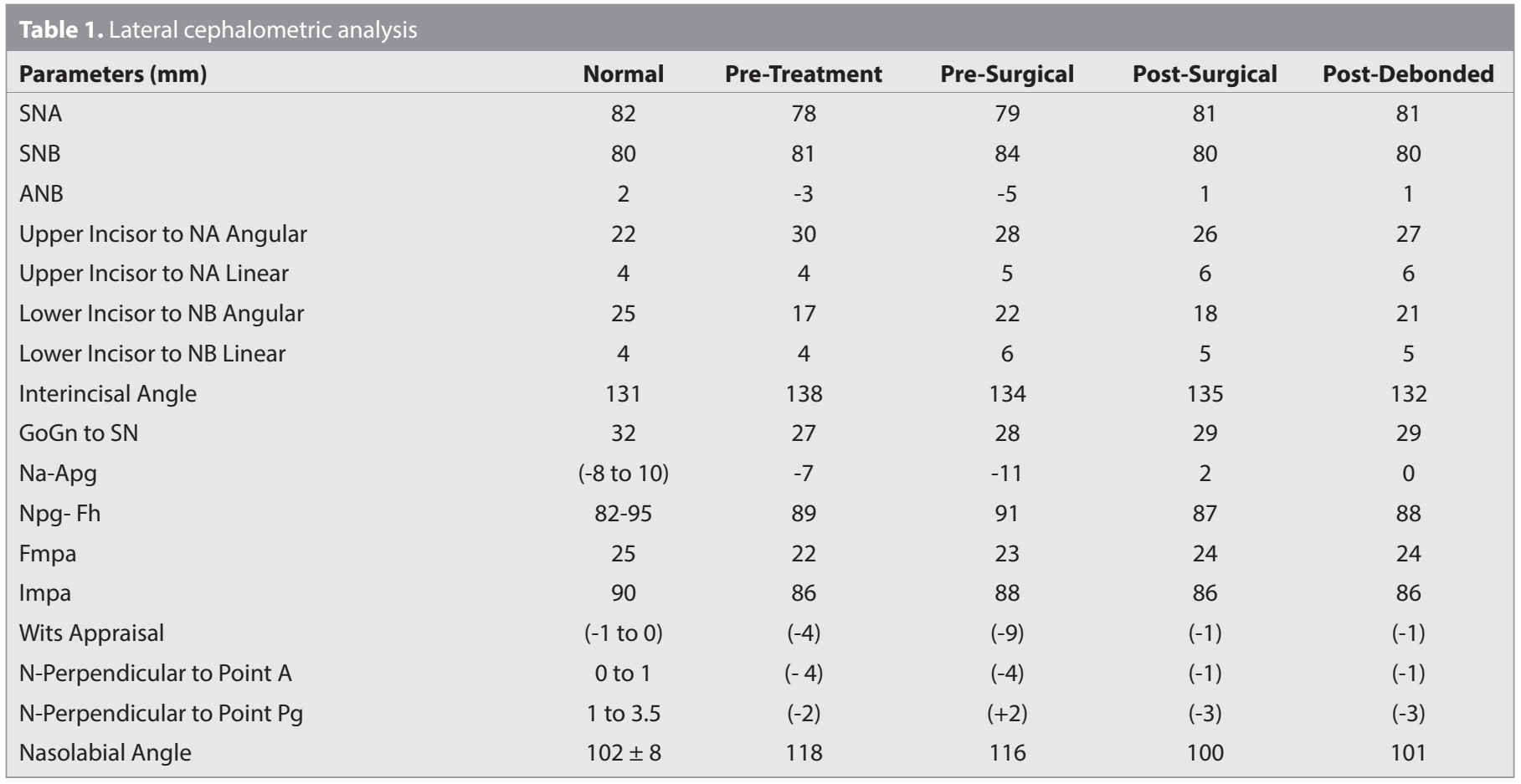

\section{Table 2. Grummon's posterioanterior cephalometric analysis}

\begin{tabular}{|c|c|c|c|c|c|}
\hline & & \multicolumn{4}{|c|}{ Linear Measurements (In Millimeters) } \\
\hline & & \multicolumn{2}{|c|}{ Right } & \multicolumn{2}{|c|}{ Left } \\
\hline & & Pre-Surgical & Post-Surgical & Pre- Surgical & Post-Surgical \\
\hline 2 & $\mathrm{Ag}-\mathrm{Me}$ & 44 & 50 & 53 & 49 \\
\hline 3 & Co-Me & 104 & 109 & 106 & 108 \\
\hline \multirow[t]{2}{*}{6} & Co-Msr & 55 & 58 & 52 & 52 \\
\hline & & \multicolumn{4}{|c|}{ Other Measurement } \\
\hline \multirow[t]{2}{*}{1} & Angle Co-Ag-Me & 125 & 123 & 125 & 125 \\
\hline & & \multicolumn{2}{|c|}{ Pre-Surgical } & \multicolumn{2}{|c|}{ Post- Surgical } \\
\hline & & Pre-Surgical & Pre-Surgical & Post-Surgical & Post-Surgical \\
\hline 1 & Upper Facial Ratio Cg-Ans : Cg-Me & $50: 120$ & 0.42 & $52: 122$ & 0.43 \\
\hline 2 & Lower Facial Ratio Ans-Me : Cg-Me & $67: 120$ & 0.56 & $67: 122$ & 0.55 \\
\hline 3 & Maxillary Ratio Ans-A1 : Ans- Me & 29:67 & 0.43 & $30: 70$ & 0.43 \\
\hline 4 & Total Maxillary Ratio Ans-A1: Cg-Me & 29:120 & 0.24 & $30: 122$ & 0.25 \\
\hline 5 & Mandibular Ratio B1-Me : Ans- Me & $37: 67$ & 0.55 & $37: 69$ & 0.54 \\
\hline 6 & Total Mandibular Ratio B1- Me : Cg- Me & $37: 120$ & 0.31 & $37: 122$ & 0.30 \\
\hline 7 & Maxillomandibular Ratio Ans- A1 : B1- Me & 29:37 & 0.78 & $30: 37$ & 0.81 \\
\hline
\end{tabular}


Hence, mandibular setback surgery was also required to correct prognathism as well as skeletal asymmetry. Since the patient had a skeletal problem, orthognathic surgery was the only viable option for correction of the sagittal discrepancy. The ideal time for surgical correction is after growth completion which is mostly after 18 years of age. However, to plan accurate surgical treatment in this patient at this age, we needed substantial evidence of the growth potential of the jaw bases. Hence, we forecasted the 4-year mandibular growth using Rickett's VTO. As displayed in Figure 3, with the VTO for this patient, we predicted that the mandible would continue to grow forward significantly leaving the maxilla behind and worsen the profile in the next 4 years. By this image, we forecasted that the soft tissue profile would turn into Class III from straight and that the patient would require surgical correction once the growth is ceased. The literature also supports the accuracy and reliability of Ricketts VTO to be almost $96 \%$.

\section{Wait-and-Watch Approach}

One option was to keep patient on routine observation, and once the growth is ceased, go for surgical correction. However, the pa-

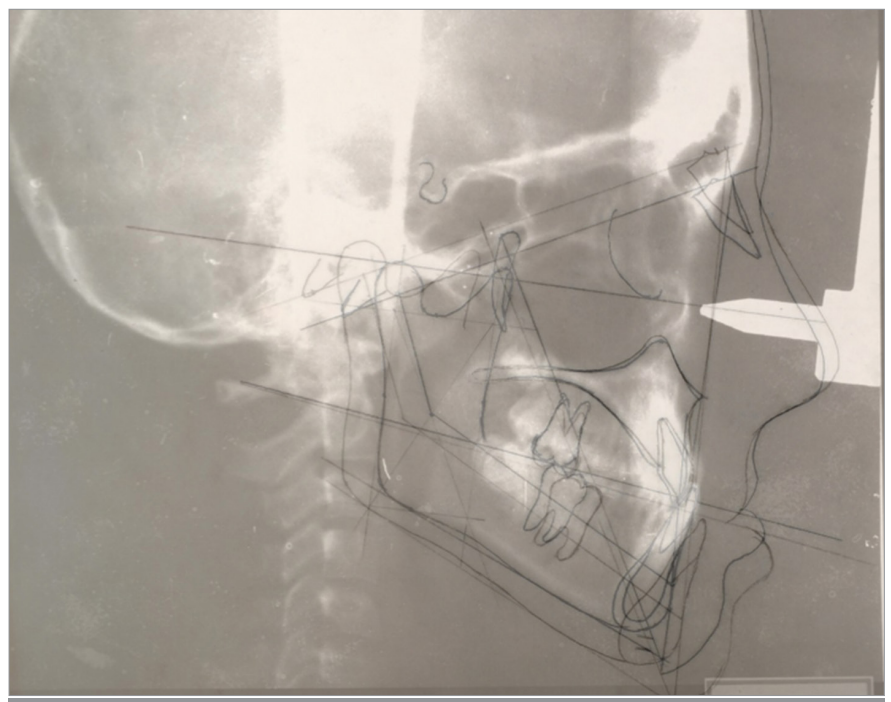

Figure 3. Rickets VTO (visual treatment objective) showing expected growth of mandible over 4 year period

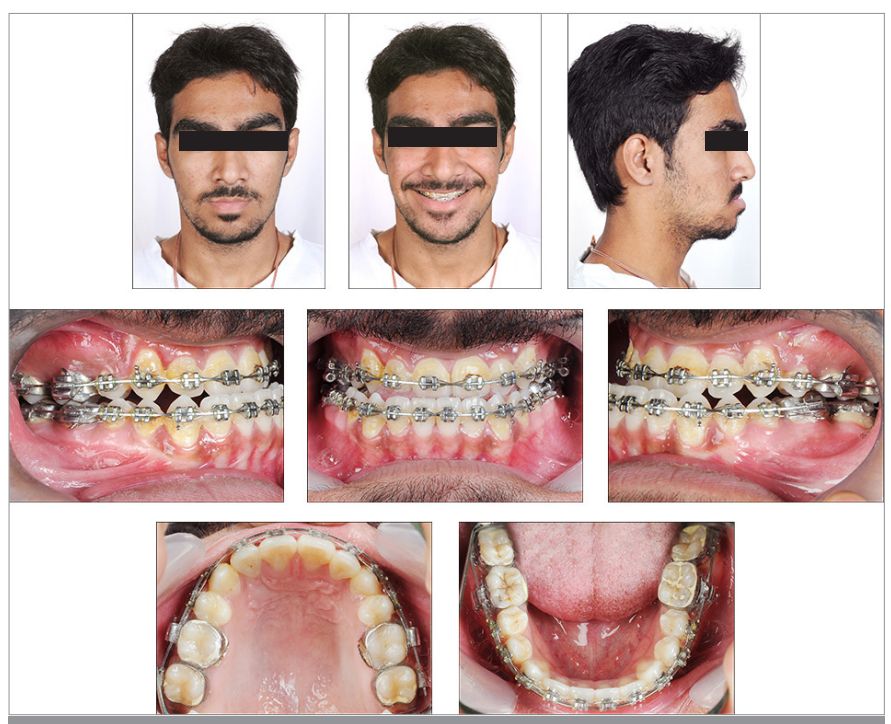

Figure 4. Presurgical photographs tient was presented with complex dentoalveolar as well as underlying skeletal malocclusion. If we had waited for growth to cease, perhaps till the age of 18 years, then it would have taken another 2 years for dental decompensation before we could send him for orthognathic surgery. At this age when he enters college for an education, peer pressure and appearance are of prime importance. Thus, parents and patient had rejected this approach.

\section{Distraction Osteogenesis}

Another option to think about was the distraction osteogenesis. However, based on the envelope of discrepancy, this treatment option would be suitable for more severe skeletal problems that may not be corrected with orthognathic surgery.

\section{TREATMENT PROGRESSION}

After keeping in mind all possible outcomes, we chose the second option, which was the extraction of upper first premolars and dentoalveolar decompensation followed by maxillary advancement and mandibular asymmetric setback. Treatment was conducted in three phases.

\section{Presurgical Orthodontics}

Treatment was begun at the age of 14 years and 8 months. Standard 0.022" inch MBT preadjusted straight wire appliance (3M Unitech) was used throughout the course of treatment. Following the extraction of upper premolars and deciduous canines, space was utilized to correct the angulation of upper anteriors and get lateral incisors and canines in proper alignment. Wire progression and space closure were done from the initial $0.014^{\prime \prime} \mathrm{NiTi}$ till $0.021 " \mathrm{x} 0.025^{\prime \prime}$ stainless steel wire with appropriate anchorage preparation (Nance appliance). Simultaneously, lower arch alignment and leveling were done, and the arch was prepared till passive 0.021 "x0.025" stainless steel wire. At the end of decompensation, molar relation was endon to Class I on the right side and Class III on the left side, canines were in Class III bilateral with $6 \mathrm{~mm}$ of reverse overjet, and midline was shifted toward right side by $2 \mathrm{~mm}$ (Figure 4). Surgical decompensation was achieved in almost 2 years and 7 months. All third molars were removed 6 months before the surgery, giving enough time for sockets to get mineralized (Figure 5).

\section{Orthognathic Surgery}

Combination of certain dental specialties may offer services with certain advantages for patients, as well as practitioners (16). Face bow transfer and articulation of anatomic models was done on the HANAU articulator (Figure 6), and two surgical wafers (first one for maxillary positioning and second one for mandibular positioning) were fabricated as per the mock surgery that was carried out on models (Figure 7). In the mock surgery on the HANAU articulator, the mounted casts were separated using a handsaw and repositioned with the help of modeling wax, leaving the 4 $\mathrm{mm}$ advancement of the maxillary cast and asymmetric setback of the mandibular cast ( $5 \mathrm{~mm}$ on right and $3 \mathrm{~mm}$ on the left side). At the age of 18 years, almost after 4 years of the beginning of the orthodontic treatment, Lefort I surgical procedure was carried out as decided, and the maxilla was repositioned $4 \mathrm{~mm}$ an- 


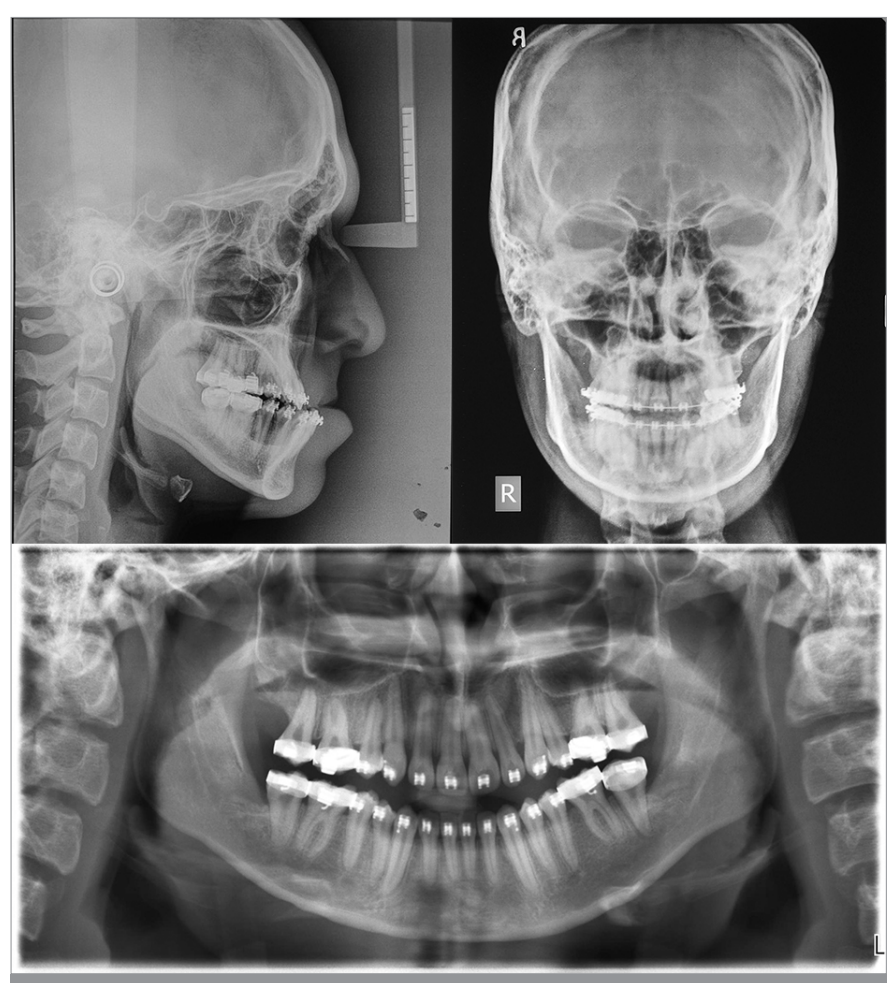

Figure 5. Presurgical radiographs
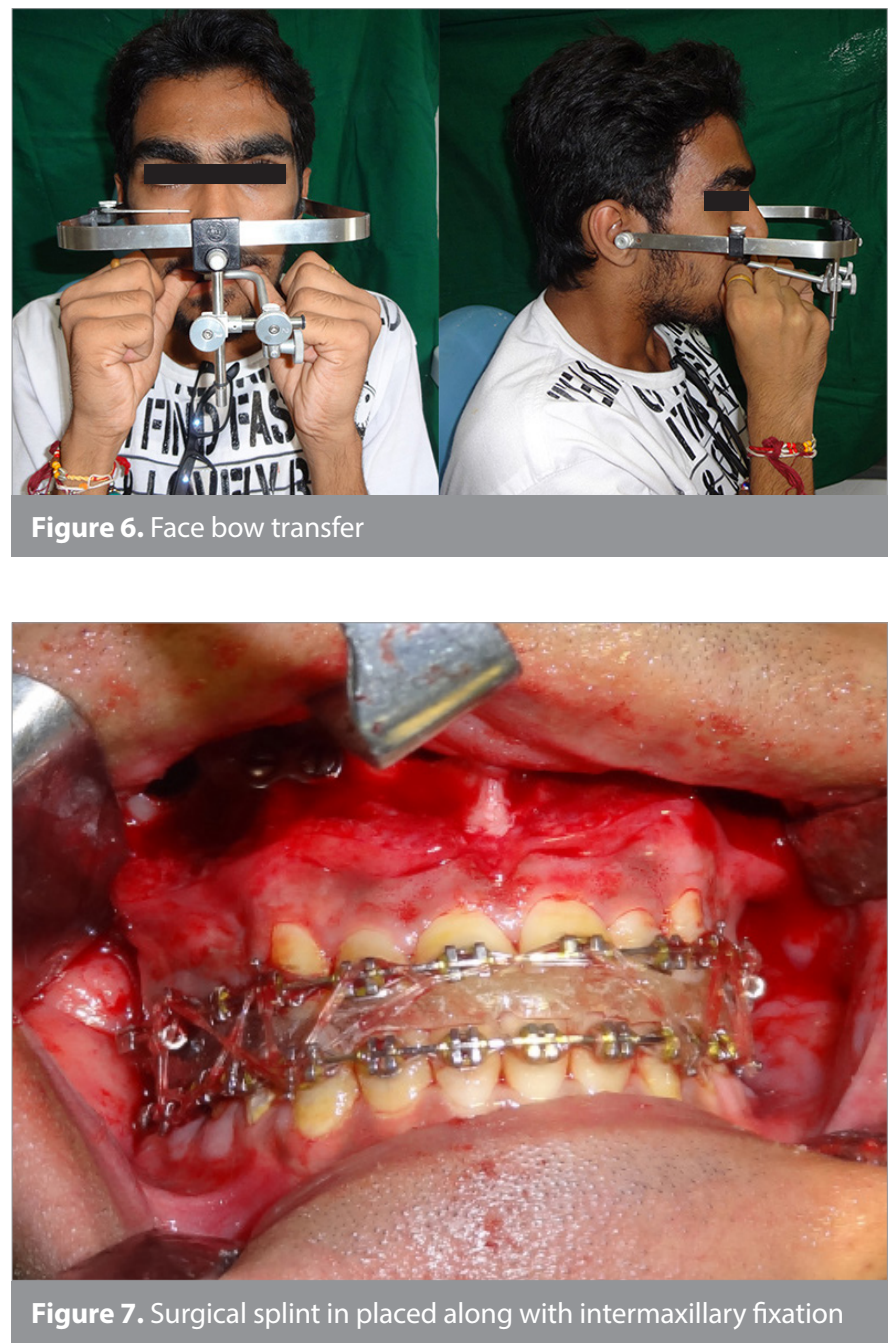

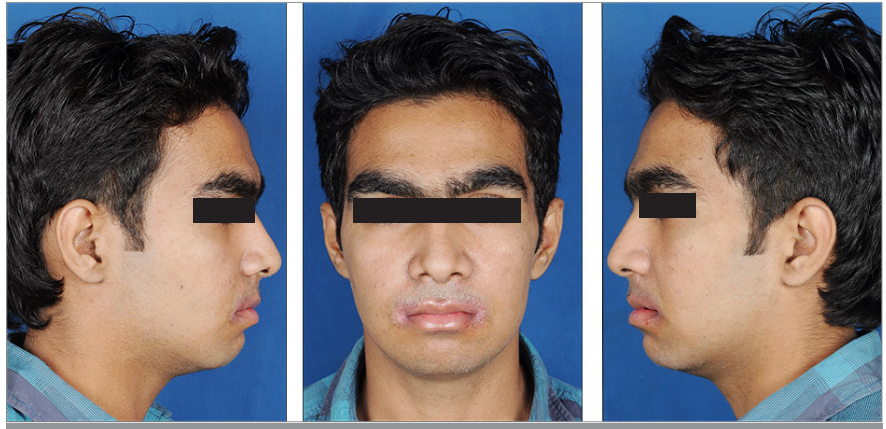

Figure 8. Extraoral photographs captured after 3 days of surgery

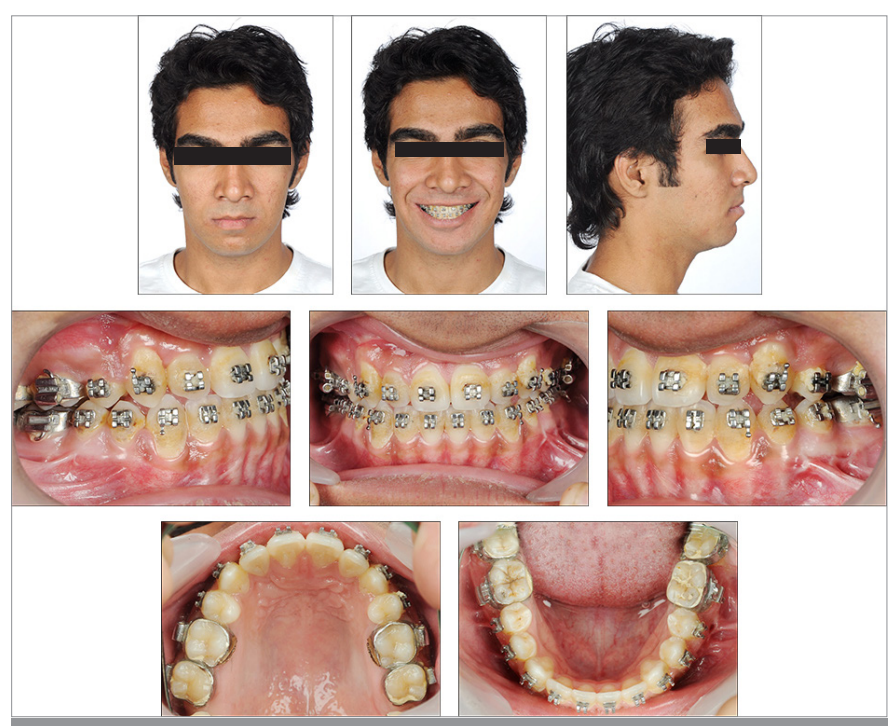

Figure 9. Post-surgical photographs
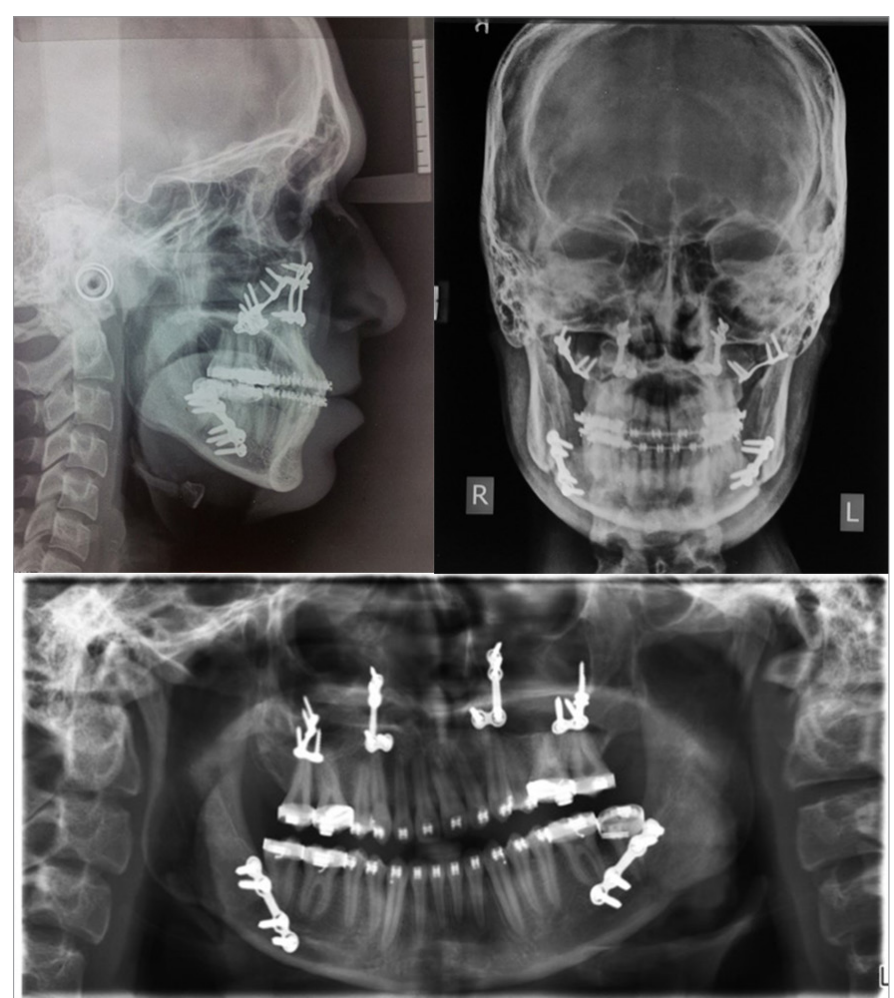

Figure 10. Post-surgical radiographs 
teriorly. At the same time, bilateral sagittal split osteotomy was performed, and the mandible was asymmetrically set back by 5 $\mathrm{mm}$ on the right side and $3 \mathrm{~mm}$ on the left side (Figure 8-10). The amount of maxillary advancement and mandibular setback was calibrated based on presurgical occlusion, profile, and STO. Initially, in the STO, only maxillary advancement was simulated. However, with only single-jaw surgery, the profile did not appear very favorable. Thus, we followed the presurgical occlusion on casts, and it was noticed that the correction of $9 \mathrm{~mm}$ on the right side and $7 \mathrm{~mm}$ on the left side was required to achieve full cusp Class II molars and Class I canines bilaterally with coincident mid-
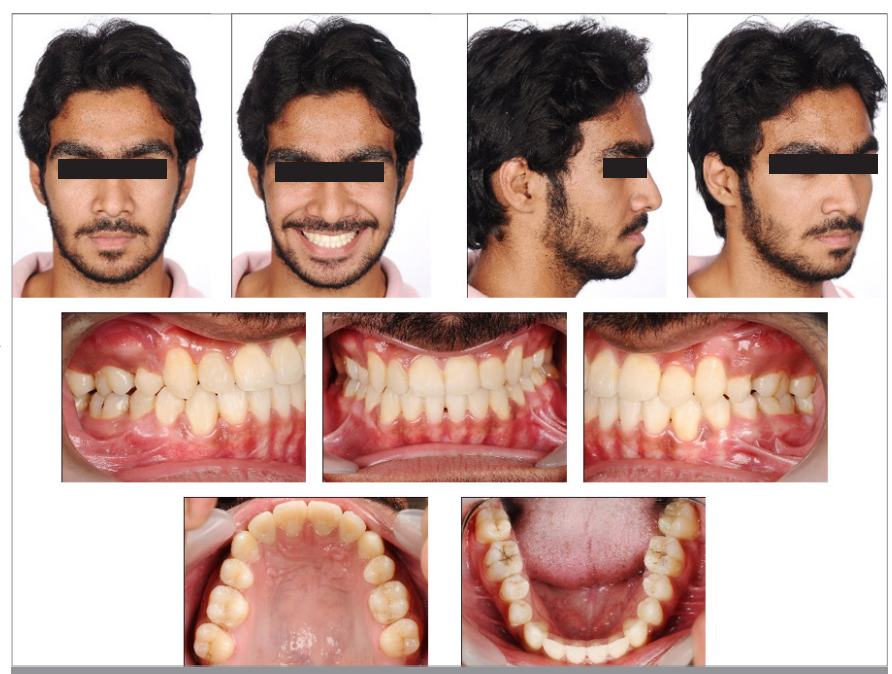

Figure 11. Post-debonded photographs

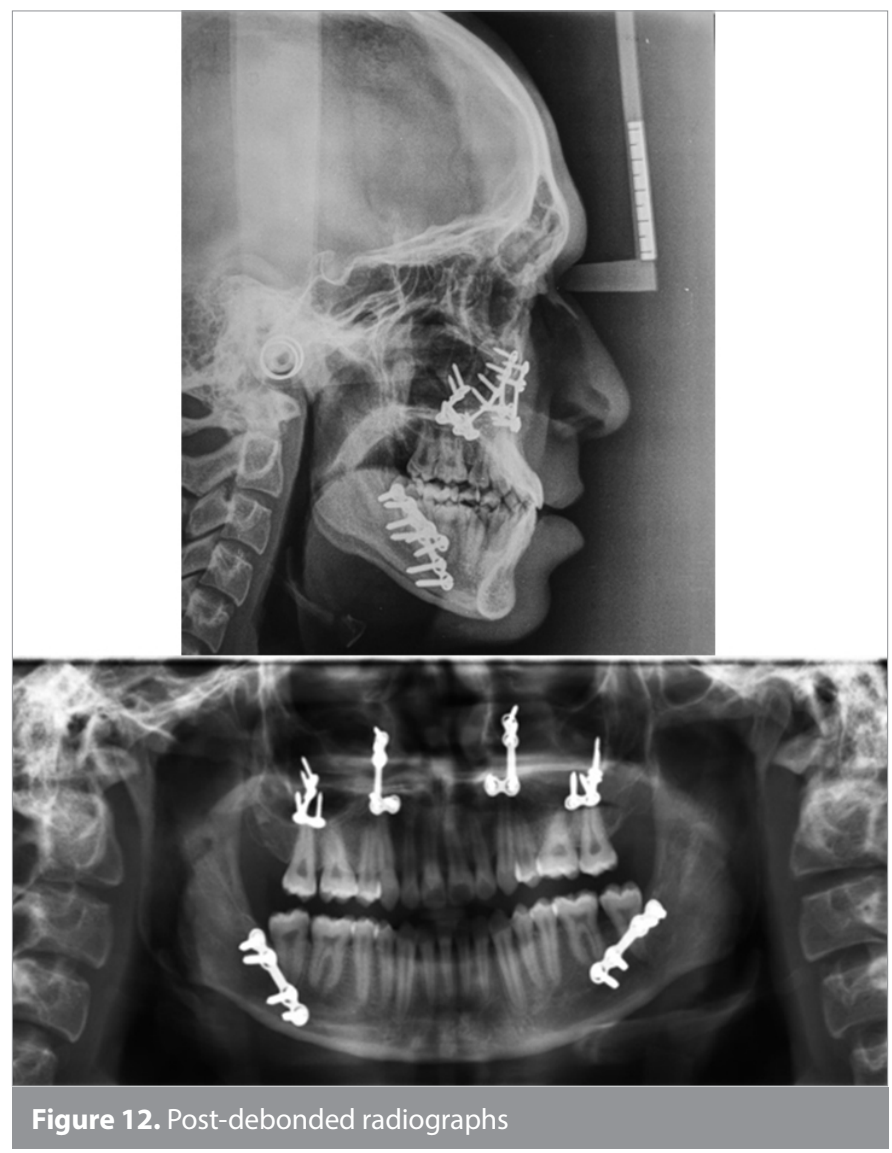

lines. Then, we simulated various combination in STO and finally concluded that the $4 \mathrm{~mm}$ maxillary advancement and asymmetrical mandibular ( $5 \mathrm{~mm}$ on right and $3 \mathrm{~mm}$ on the left side) setback were the most favorable surgical corrections.

\section{Postsurgical Orthodontics}

Postsurgical orthodontics was initiated after a period of 4 weeks. Archwires were sequentially changed from $0.017^{\prime \prime} X 0.025^{\prime \prime} \mathrm{NiTi}$ to $0.019^{\prime \prime} X 0.025^{\prime \prime}$ stainless steel. Finishing and settling of the final occlusion were carried out by short settling elastics. Mild Class 3 elastics were used in this phase.

The total duration of treatment was 4 years and 6 months. At the time of debonding, the patient was having Class II molar and Class I canine relationship bilaterally, and upper and lower midlines were coinciding. Also, the soft tissue profile was mildly convex and overjet, and the overbite was $2 \mathrm{~mm}$ with a consonant smile arch (Figure 11, 12). Cephalometric superimposition was carried out on the SN plane, maxillary plane (ANS-PNS), and mandibular symphysis. This reflects the maxillomandibular movement in the sagittal plane as per our surgical planning (Figure 13).

\section{DISCUSSION}

Whether to wait till growth is over or to plan an orthognathic surgery right away has always been part of an active debate in

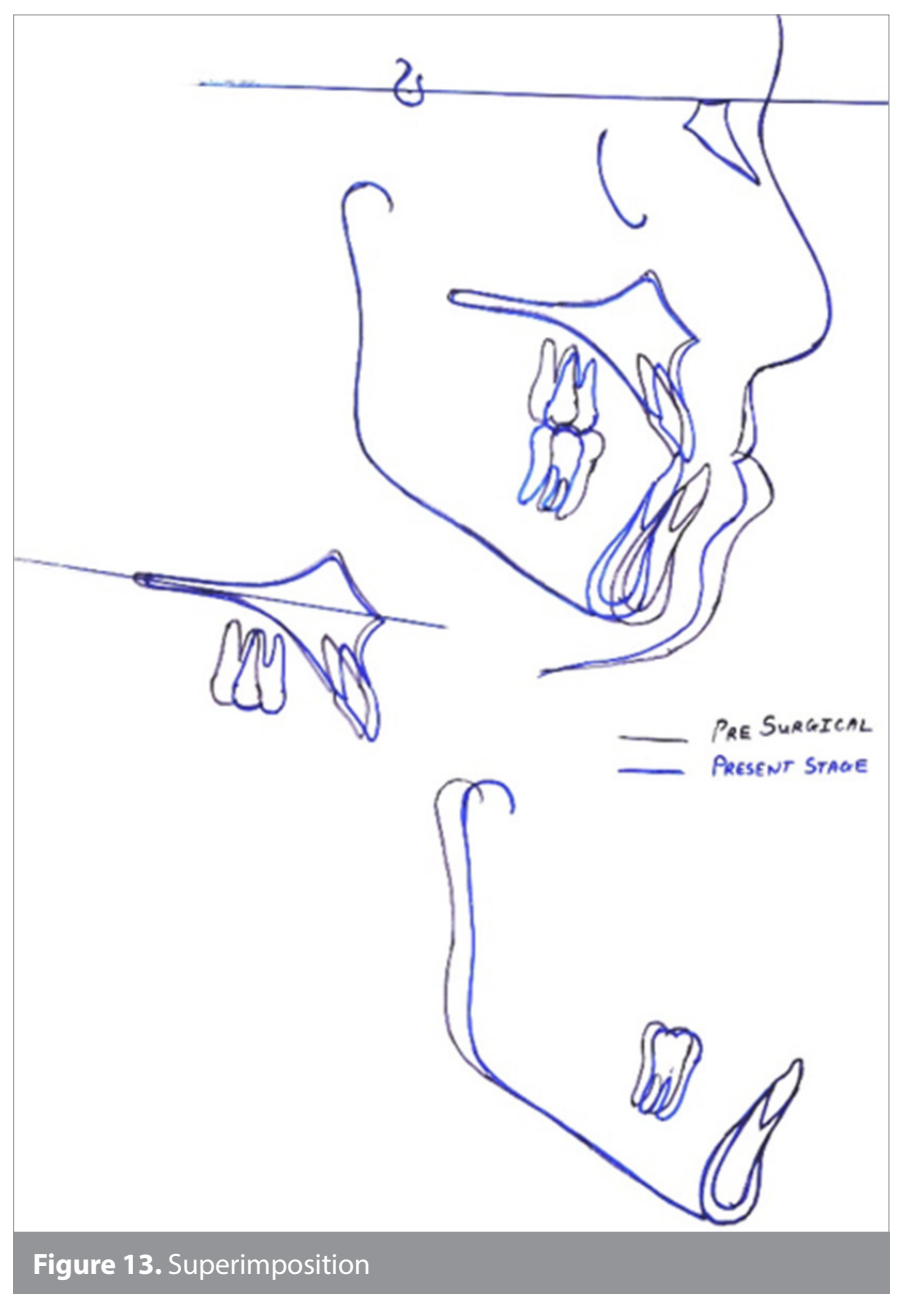


orthodontics. Choosing a nonsurgical compromised treatment or delaying orthognathic surgery until growth is complete could be damaging to the patient's self-image. Delaying treatment until adulthood can exacerbate problems related to pain, speech, airway, anatomy, occlusion, aesthetics, temporomandibular joint function, masticatory function, and psychosocial factors (17). To overcome these issues, orthodontists started to incline toward an early surgical treatment in the growing phase. However, the determination of the growth rate or vector can be challenging. In the past, few authors have attempted to predict the facial growth using various methods such as manual or computerized; and two-dimensional cephalometric or three-dimensional conebeam computed tomography (CBCTs). Out of these methods, Rickett's VTO has been reported to be one of the most precise techniques. In a study that included Turkish children, Kocadereli and Telli (18) reported statistically significantly higher correlations between predicted and actual measurements of various parameters. In another independent study on Turkish adolescents, Enacar (19) concluded that there was a high correlation between the predicted and actual measurements, and mandibular parameters were accurately predicted. In both of these studies, the authors used Rickett's long-range growth prediction as a tool. Furthermore, by presenting this case, we tried to elucidate that even after so many years following its introduction, Rickett's growth prediction is still working as an efficient diagnostic tool.

\section{CONCLUSION}

The treatment of dentofacial deformities of young patients is complex, especially when transverse and sagittal discrepancies exist, and it requires orthodontic treatment combined with orthognathic surgery to achieve stable, functional, and aesthetic results $(20,21)$. Prediction must be performed before finalizing the treatment plan for growing patients. For this particular case, orthognathic surgery has not have been considered at a young age since the profile was not severely concave. However, by Rickett's method, it was predicted how the mandible would grow and how the patient would look in 4 years. Rickett's prediction played a paramount role in deciding our final treatment plan. Thus, one should always put an emphasis the prediction method when treating growing children.

Informed Consent: Verbal informed consent was obtained from the patients who participated in this study.

Peer-review: Externally peer-reviewed.

Author Contributions: Concept - V.G., M.F, P.D.; Design - V.G., M.F, P.D.; Supervision - M.F.; Data Collection and/or Processing - V.G., H.P., J.H.; Analysis and/or Interpretation - V.G., H.P., J.H.; Writing Manuscript - V.G., J.H.; Critical Reviews - M.F.

Conflict of Interest: The authors have no conflict of interest to declare.

Financial Disclosure: The authors declared that this study has received no financial support.

\section{REFERENCES}

1. Kapadia RM, Shah AP, Diyora SD, Rathva VJ. Non-surgical treatment of skeletal Class III malocclusion. BMJ Case Rep 2014: bcr2013202326. [CrossRef]

2. Hardy D, Cubas Y, Orellana M. Prevalence of angle class III malocclusion: A systematic review and meta-analysis. O J Epi 2012; 2: 75-82. [CrossRef]

3. Lew KK, Foong WC, Loh E. Malocclusion prevalence in an ethnic Chinese population. Aus Dent J 1993; 38: 442-9. [CrossRef]

4. Tang EL. Occlusal features of Chinese adults in Hong Kong. Aus Orthod J 1994; 13: 159-63.

5. Tang EL. The prevalence of malocclusion amongst Hong Kong male dental students. Bri J Orthod 1994; 21: 57-63. [CrossRef]

6. Woon KC, Thong YL, AbdulKadir R. Permanent dentition occlusion in Chinese, Indian and Malay groups in Malaysia. Aus Orthod J 1989; 11:45-8.

7. Soh J, Sandham A, Chan YH. Occlusal status in Asian male adults: Prevalence and ethnic varia- tion. Angle Orthod 2005; 75: 81420.

8. Gauba K, Ashima G, Tewari A, Utreja A. Prevalence of malocclusion and abnormal oral habits in North Indian rural children. J Ind Soc Ped and Prev Dent 1998; 16: 26-30.

9. Baumrind S. Prediction in the planning and conduct of orthodontic treatment. In: Melson B, ed. Current controversies in orthodontics. Chicago: Quintessance 1991; 25-43.

10. Burstone $\mathrm{CJ}$. Process of maturation and growth prediction. Am J Orthod 1963;49:907-19. [CrossRef]

11. Ricketts RM. Planning treatment on the basis of the facial pattern and an estimate of its growth. Angle Orthod 1957; 27: 14-37.

12. Mitchell DL, Jordan JF, Ricketts RM. Arcial growth with metallic implants in mandibular growth prediction. Am J Orthod 1975; 68: 6559. [CrossRef]

13. Tweed $\mathrm{CH}$. Treatment planning and therapy in the mixed dentition. Am J Orthod 1963; 49: 881-906. [CrossRef]

14. Ricketts RM. Facial and denture changes during orthodontic treatment as analysed from the temporomandibular joint. Am J Orthod 1955; 41: 163-79. [CrossRef]

15. Nagori H, Fattahi T. Maxillary Advancement Surgery and Nasolabial Soft Tissue Changes. IOSR J Dent and Med Sci 2017: 3: 23-9. [CrossRef]

16. Jones MB, Nagori H, Litschel K, Swigler W, Farill-Guzman J. Parental Preference for Dual-Trained Orthodontist. J Orthod Endod 2017; 3: 2. doi: 10.21767/2469-2980.100042. [CrossRef]

17. Wolford LM, Karras SC, Mehra P. Considerations for orthognathic surgery during growth, part 1: mandibular deformities. Am J Orthod Dentofacial Orthop 2001; 119: 95-101. [CrossRef]

18. Kocadereli I, Telli AE. Evaluation of Ricketts' long-range growth prediction in Turkish children. Am J Orthod Dentofacial Orthop 1999; 115: 515-20. [CrossRef]

19. Enacar A. Ricketts'in "mandibulanın arkial büyümesi" kuramının ve uzun süreli tah- min yönteminin ülkemiz bireylerinde deerlendirilmesi (longitudinal arastırma). Büyüme Gelisim ve Ortodonti, Tübitak Yayın Daıtım Daire Baskanligi, Ankara, 1991.

20. Guloy R, Nagori H, Gandhi V. Orthodontic and Surgical Correction of Class-III Malocclusion with Excellence Facial Aesthetic Results- Case Report. IOSR J Dent Med Sci 2017; 16: 82-91.

21. Gandhi V, Malek F. Orthognathic Surgery and Facial Changes - A Review. J Orthod Endod 2018; 4: 1. doi: 10.21767/2469-2980.100050. [CrossRef] 